\title{
Study on the effectiveness of orientation class about rational prescription on interns
}

\author{
Reema T. Thottol ${ }^{1}$, Anuradha M. ${ }^{2}$, Sajna M. V. ${ }^{3}$
}

${ }^{1}$ Department Pharmacology, Goverment Medical College, Kozhikode, University of Calicut, Kerala, India ${ }^{2}$ Department of Pharmacology, Goverment Medical College, Idukki, University of Calicut, Kerala, India

${ }^{3}$ Department of Community Medicine, Government Medical College, University of Calicut, Thrissur, Kerala, India

Received: 28 September 2016 Revised: 12 December 2016 Accepted: 15 December 2016

*Correspondence to:

Dr. Reema T. Thottol,

Email:

reemathotto175@gmail.com

Copyright: (C) the author(s), publisher and licensee Medip Academy. This is an openaccess article distributed under the terms of the Creative Commons Attribution NonCommercial License, which permits unrestricted noncommercial use, distribution, and reproduction in any medium, provided the original work is properly cited.

\begin{abstract}
Background: Prescribing is one aspect of patient care where it is possible to do considerable harm if not done judiciously. The first experience of unsupervised prescribing begins during the internship year. Junior doctors are the most frequent prescribers in the hospital setting and are reported to make most of the prescribing errors. The Objective of the study was to study on the effectiveness of orientation class about rational prescription on interns.

Methods: Sample size was 100 students attending orientation course at the beginning of intern ship. This study was done in Government Medical College Kozhikode, after getting ethics Committee approval. Total of 100 interns were included in the study. Pre-test was conducted to assess the prescribing skills by giving one case scenario, followed by a class on rational prescription writing. 14 questionnaires are made and prescription quality is assessed. Post-test was given after 2 weeks where the same previous case scenario repeated.

Results: This study shows that orientation class about rational prescription during the beginning of internship improves the quality of prescription writing. Among the 14 parameters made for assessment of quality of prescription thirteen shows significant $\mathrm{P}$ value. So it is very effective to take orientation class about rational prescription during the internship period.

Conclusions: It is very effective to take orientation class about rational prescription and periodic updating during the internship period improves the quality of prescription. As they learn the basics of prescription writing during their third semester only. Thus we can reduce the prescribing errors.
\end{abstract}

Keywords: Prescription, Rational prescription

\section{INTRODUCTION}

Prescribing is one aspect of patient care where it is possible to do considerable harm if not done judiciously. Most junior doctors are unaware of the fact that prescribing errors may contribute to a significant rise in reported hospital adverse events and subsequent medico legal problems.
The essence of good prescription writing is to ensure that the pharmacist knows exactly which drug formulation and dosage to dispense and the patient has clear written instruction for self-administration of the prescribed drug. ${ }^{1-3} \mathrm{~A}$ prescription is a legal document that carries regulations to ensure safe use and to comply with governmental regulations. The first experience of unsupervised prescribing begins during the internship year. Junior doctors are the most frequent prescribers in 
the hospital setting and are reported to make most of the prescribing errors.

Knowing what drug to prescribe to which patient does not necessarily translate to a good prescription. ${ }^{3}$ Considering the fact that the majority of prescriptionrelated errors in the hospital environment are made by junior doctors. It is necessary to educate the interns and develop interventions that will improve the prescribing qualities.

It is not easy to change the prescribing habits of experienced doctors, thus there is the hope that educating junior doctors to prescribe according to standard guide lines may be a more effective intervention. ${ }^{3,4}$ This study was therefore aimed to determine the knowledge junior doctors have about prescribing errors, their perception of events that constitute a prescribing error, factors that contribute to prescribing errors, medicines less confidently prescribed and circumstances in which they were prone to making prescribing errors. Inadequate knowledge or competence and incomplete information about clinical characteristics of individual patients can result in prescribing faults, including use of potentially unfamiliar medications. Interns have a low selfawareness of prescribing errors and would likely benefit from theoretical and practical teaching on what constitute a properly written prescription with frequent assessment of knowledge and skills acquired. This would likely improve their confidence in rational medication prescribing during and after their internship training. An unsafe working environment and inadequate supervision have also been identified as important underlying factors that contribute to prescription errors.

Aim of the study was to assess the effectiveness of orientation class about rational prescribing on fresh interns.

\section{Objectives}

1. To assess the effectiveness of orientation class about rational prescribing on fresh interns

2. To assess the prescribing skills of fresh interns before starting internship.

\section{METHODS}

Sample size was 100 students attending orientation course at the beginning of intern ship.

This study was done in Government medical college Kozhikode, after getting ethics Committee approval. Total of 100 interns were included in the study. Pre-test was conducted to assess the prescribing skills by giving one case scenario, followed by a class on rational prescription writing. 14 questionnaires are made and prescription quality is assessed. Post-test was given after 2 weeks where the same previous case scenario repeated.
Design of the study was interventional.

For prescribing quality assessment, following parameters are used: ${ }^{6,7}$

1. Is the prescribers name on the prescription legible?

2. Is the prescriber's information on the prescription adequate?

3. Is the patient's information on the prescription adequate?

4. Is the diagnosis on the prescription clearly written?

5. Is there an indication for the drug?

6. Is the dosage correct?

7. Are the directions for the administration correct?

8. Is the duration of therapy acceptable?

9. Is the medication being prescribed by generic name?

10. Is the medication available in the formulary or essential drug list?

11. Is the medications name on the prescription clearly written?

12. Are there clinically significant drug-disease /condition interactions?

13. Are there clinically significant drug-drug interactions?

14. Is this drug the cheapest compared to other alternatives for the same indication?

Using these questionnaires we can assess the quality of prescription both before and after the orientation class.

\section{Statistical analysis}

Total of 100 case scenarios collected before orientation class on rational prescription and 100 case scenarios after the orientation class. Statistical analysis was done using SPSS software version 17. Test applied was chi square test and Fischers exact $\mathrm{t}$ - test.

\section{RESULTS}

All parameters compared both before and after orientation class.

Comparisons showed that $\mathrm{P}$ values were highly significant for majority of questionnaires.

Table 1: Clarity of prescribers name in the prescription.

\begin{tabular}{|lll|l|}
\hline Pre-test & Post-test & Chi square value & p-value \\
\hline $28.1 \%$ & $71.9 \%$ & 87.77 & 0.000 \\
\hline
\end{tabular}

So there is significant improvement after orientation class.

\section{Table 2: Adequacy of prescriber's information on the prescription.}

\begin{tabular}{|lll|l|}
\hline Pre-test & Post-test & Chi square value & p-value \\
\hline $23.7 \%$ & $76.3 \%$ & $1.063 \mathrm{E} 2$ & 0.000 \\
\hline
\end{tabular}


Significant change noted after orientation class.

Table 3: Adequacy of patient information on the prescription.

\begin{tabular}{|llll|}
\hline Pre-test & Post-test & Chi square value & p-value \\
\hline $27.7 \%$ & $72.3 \%$ & 89.158 & 0.000 \\
\hline
\end{tabular}

Significant improvement noted.

Table 4: Whether diagnosis on the prescription written clearly.

\begin{tabular}{|llll|}
\hline Pre-test & Post-test & Chi square value & p-value \\
\hline $27.7 \%$ & $72.3 \%$ & 28.195 & 0.000 \\
\hline
\end{tabular}

Diagnosis clearly written in prescription after the orientation class. Significant improvement noted.

Table 5: Whether there is an indication for the drug.

\begin{tabular}{|lcll|}
\hline Pre-test & Post-test & Chi square value & p-value \\
\hline $44.7 \%$ & $55.3 \%$ & 3.569 & 0.000 \\
\hline Pre-test & - & & \\
\hline $23.7 \%$ & $76.3 \%$ & $1.063 \mathrm{E} 2$ & 0.000 \\
\hline
\end{tabular}

Here also P-value is significant.

Table 6: Whether the drug dosage correct.

\begin{tabular}{|llll|}
\hline Pre-test & Post-test & Chi square value & p-value \\
\hline $42.9 \%$ & $57.1 \%$ & 3.922 & 0.000 \\
\hline
\end{tabular}

Table 7: Direction for the administration of drug is correct.

\begin{tabular}{|llll|}
\hline Pre-test & Post-test & Chi square value & p-value \\
\hline $38 \%$ & $62 \%$ & 11.520 & 0.001 \\
\hline
\end{tabular}

Table 8: Whether duration of therapy is acceptable.

\begin{tabular}{|llll|}
\hline Pre-test & Post-test & Chi square value & p-value \\
\hline $30 \%$ & $56 \%$ & 13.798 & 0.000 \\
\hline
\end{tabular}

Drug dosage, administration and duration are clearly written after the orientation class. Significant improvement present.

Table 9: Whether the medication prescribed by generic name.

\begin{tabular}{|llll|}
\hline Pre-test & Post-test & Chi square value & p-value \\
\hline $35.8 \%$ & $64.2 \%$ & 18.065 & 0.000 \\
\hline
\end{tabular}

After the rational prescription class drugs are written in generic name. $\mathrm{P}$ value is significant.
Table 10: Whether the prescribed medication is available in the drug formulary.

\begin{tabular}{|lll|l|}
\hline Pre-test & Post-test & Chi square value & p-value \\
\hline $39 \%$ & $61 \%$ & 25.977 & 0.000 \\
\hline
\end{tabular}

Most of the prescribed medications are in the drug formulary. It is significant.

Table 11: Whether the medication name on the prescription clearly written.

\begin{tabular}{|lll|l|}
\hline Pre-test & Post-test & Chi square value & p-value \\
\hline $43.8 \%$ & $56.2 \%$ & 12.500 & 0.000 \\
\hline
\end{tabular}

Medication name on the prescription is clearly written So significant improvement noted.

Table 12: Clinically significant interaction between drug and disease.

\begin{tabular}{|lll|l|}
\hline Pre-test & Post-test & Chi square value & p-value \\
\hline $49.7 \%$ & $76.3 \%$ & 0.338 & 0.500 \\
\hline
\end{tabular}

No significance.

Table 13: Whether any clinically significant drugdrug interaction.

\begin{tabular}{|lll|l|}
\hline Pre-test & Post-test & Chi square value & p-value \\
\hline $49 \%$ & $51 \%$ & 5.078 & 0.030 \\
\hline
\end{tabular}

$P$ value is significant.

Table 14: Whether the drug is cheap for the specific condition.

\begin{tabular}{|lll|l|}
\hline Pre-test & Post-test & Chi square value & p-value \\
\hline $47.6 \%$ & $52.4 \%$ & 10.424 & 0.001 \\
\hline
\end{tabular}

$\mathrm{P}$ value is significant.

\section{DISCUSSION}

The first experience of unsupervised prescribing begins during the internship year. ${ }^{3-5}$ Junior doctors are the most frequent prescribers in the hospital setting and are reported to make most of the prescribing errors. Basics of prescription writing they got only from their initial third and fourth semesters. ${ }^{4,6,7}$ It is necessary to educate the interns and develop interventions that will improve the prescribing qualities. This study shows that orientation class about rational prescription during the beginning of internship improves the quality of prescription writing. Among the 14 parameters made for assessment of quality of prescription thirteen shows significant $P$ value. So it is very effective to take orientation class about rational prescription during the internship period. 


\section{CONCLUSION}

It is very effective to take orientation class about rational prescription and periodic updating during internship. Thus we can reduce the number of prescribing errors in the hospitals and can improve the quality of prescription.

Funding: No funding sources

Conflict of interest: None declared

Ethical approval: The study was approved by the Institutional Ethics Committee

\section{REFERENCES}

1. Bertram G, Katzung. Basic clinical pharmacology $11^{\text {th }}$ edition. 2009;1:1139-1169.

2. Goodman and Gillmans pharmacological Basis of Therapeutics $12^{\text {th }}$ edn. $1880-1882$.

3. Satoskar RS, Nirmala N REGE, Bhandarkar SD. Pharmacology and pharmacotherapeutics. $24^{\text {th }}$ edition; 2015:53-54.
4. Suthar JV, Patel VJ, Vaishnav B. Quality of prescribing for hypertension and bronchial asthma at a tertiary health care facility. India using prescription quality index tool. Journal of Basic and clinical Pharmacy. 2015;6(1):1-6.

5. Satoskar RS, Bandarkar SD, Rege NN. Pharmacologyand pharmacotherapeutics. $20^{\text {th }}$ edn; 1973:975-990.

6. Thripathi KD. Essentials of medical pharmacology. $6^{\text {th }}$ edn; 72-73.

7. Islam Z, Rahman F, Mossaddek AS, RJ Rozario, Akhter S, Jahan I, et al. Journal of Applied Pharmaceutical science. Assessment of Bangladesh interns Knowledge of Pharmacology and Therapeutics for prescribing. 2014;4(04):043-51.

Cite this article as: Thottol RT, Anuradha M, Sajna MV. Study on the effectiveness of orientation class about rational prescription on interns. Int J Basic Clin Pharmacol 2017;6:89-92. 